\title{
Endothelium-dependent vasodilation in response to Pseudomonas aeruginosa lipopolysaccharide: an in vitro study on canine arteries
}

P.R.B. Evora, S. Ekin, P.J. Pearson and H.V. Schaff
Cardiac Surgical Research and the Section of Cardiovascular Surgery, Mayo Clinic and Mayo Foundation, Rochester, MN, USA

\section{Correspondence}

P.R.B. Evora

Rua Rui Barbosa, 367, 70 andar

14015-120 Ribeirão Preto, SP

Brasil

Fax: +55-16-610-9890

E-mail: prbevora@ keynet.com.br

Research supported in part by Mayo Foundation (USA) and CN Pq. Publication supported by FAPESP.

Received December 4, 1997 Accepted July 7, 1998

\section{Abstract}

Early systemic arterial hypotension is a common clinical feature of Pseudomonas septicemia. To determine if Pseudomonas aeruginosa endotoxin induces the release of endothelium-derived nitric oxide (EDNO), an endogenous nitrovasodilator, segments of canine femoral, renal, hepatic, superior mesenteric, and left circumflex coronary arteries were suspended in organ chambers (physiological salt solution, $95 \% \mathrm{O}_{2} / 5 \% \mathrm{CO}_{2}, \mathrm{pH} 7.4,37^{\circ} \mathrm{C}$ ) to measure isometric force. In arterial segments contracted with $2 \mu \mathrm{M}$ prostaglandin $\mathrm{F}_{2 \alpha}$, Pseudomonas endotoxin (lipopolysaccharide (LPS) serotype 10(Habs) from Pseudomonas aeruginosa $(0.05$ to $0.50 \mathrm{mg} / \mathrm{ml})$ ) induced concentration-dependent relaxation of segments with endothelium $(\mathrm{P}<0.05)$ but no significant change in tension of arteries without endothelium. Endothelium-dependent relaxation in response to Pseudomonas LPS occurred in the presence of $1 \mu \mathrm{M}$ indomethacin, but could be blocked in the coronary artery with $10 \mu \mathrm{M} \mathrm{N} \mathrm{N}^{\mathrm{G}}$-monomethyl-L-arginine (LNMMA), a competitive inhibitor of nitric oxide synthesis from Larginine. The inhibitory effect of L-NMMA on LPS-mediated vasorelaxation of the coronary artery could be reversed by exogenous $100 \mu \mathrm{M}$ L-arginine but not by $100 \mu \mathrm{M} \mathrm{D}$-arginine. These experiments indicate that Pseudomonas endotoxin induces synthesis of nitric oxide from L-arginine by the vascular endothelium. LPS-mediated production of EDNO by the endothelium, possibly through the action of constitutive nitric oxide synthase (NOSc), may decrease systemic vascular resistance and may be the mechanism of early hypotension characteristic of Pseudomonas septicemia.

\section{Introduction}

Bacteremia caused by Pseudomonas aeruginosa is a significant source of morbidity and mortality among hospitalized patients (1). Clinically, sepsis from Pseudomonas aeruginosa may manifest as systemic arterial hypotension (2) which can progress to septic shock (3). Indeed, in a study of 385
Key words

- Endothelium-derived

relaxing factor

- EDRF

- Nitric oxide

- Hypotension

- Sepsis patients with nosocomial infections, early hypotension was a predictor of Pseudomonas as the etiologic agent (4). Endotoxin, a lipopolysaccharide (LPS) found in gramnegative bacteria, is considered to be the principal toxin responsible for the clinical expression of sepsis in these infections $(5,6)$. When infused into experimental animals, Pseudomonas LPS acutely induces hypoten- 
sion due to a decrease in peripheral resistance $(7,8)$. However, the pathophysiologic mechanism of this decrease in peripheral vascular resistance is not absolutely clear.

The vascular intima releases endothelium-derived relaxing factor (EDRF) which causes vasodilation of the underlying vascular smooth muscle (9). The active component of EDRF is the nitric oxide (NO) radical $(10,11)$, which is also the active component of nitrovasodilators such as sodium nitroprusside and nitroglycerine (12). The purpose of this experiment was to determine if Pseudomonas LPS could induce endothelium-dependent relaxation of canine arteries in "organ chambers" in in vitro studies, and if the relaxation could be inhibited by $\mathrm{N}^{\mathrm{G}}$ monomethyl-L-arginine (L-NMMA), a blocker of nitric oxide synthesis from Larginine.

\section{Material and Methods}

Heartworm-free mongrel dogs $(25-30 \mathrm{~kg})$ of either sex were anesthetized $i v$ with 30 $\mathrm{mg} / \mathrm{kg}$ pentobarbital sodium (Fort Dodge Laboratories, Inc., Fort Dodge, IA) and exsanguinated via the carotid arteries. The chest was quickly opened and the heart was harvested and immersed in cool, oxygenated physiological salt solution of the following composition: $118.3 \mathrm{mM} \mathrm{NaCl}, 4.7 \mathrm{mM} \mathrm{KCl}$, $1.2 \mathrm{mM} \mathrm{MgSO}_{4}, 1.22 \mathrm{mM} \mathrm{KH}_{2} \mathrm{PO}_{4}, 2.5 \mathrm{mM}$ $\mathrm{CaCl}_{2}, 25.0 \mathrm{mM} \mathrm{NaHCO} 3,0.016 \mathrm{mM} \mathrm{Ca}-$ EDTA, and $11.1 \mathrm{mM}$ glucose (control solution). The femoral, renal, hepatic, and superior mesenteric arteries were also harvested and immersed in control solution. The procedures and handling of the animals were reviewed and approved by the Institutional Animal Care and Use Committee of the Mayo Foundation.

\section{In vitro experiments}

Canine left circumflex coronary arteries were dissected free of connective tissue and placed in control solution. Femoral, renal, hepatic, and superior mesenteric arteries were also cleaned of loose connective tissue. Segments (4-5 mm in length) of blood vessel were prepared with special care not to touch the intimal surface. In some of the segments in which vascular smooth muscle function was to be tested without the influence of the endothelium, the endothelium was removed by gently rubbing the intimal surface of the blood vessel with a pair of watchmakers' forceps. This procedure removes endothelium but does not affect the ability of vascular smooth muscle to contract or relax (13).

Coronary, renal, femoral, hepatic, and superior mesenteric artery segments, with and without endothelium, were suspended in organ chambers $(25 \mathrm{ml})$ filled with control solution maintained at $37^{\circ} \mathrm{C}$ and bubbled with $95 \% \mathrm{O}_{2} / 5 \% \mathrm{CO}_{2}, \mathrm{pH} 7.4$. Two stainless steel clips passed through the vessel lumen suspended each ring. One clip was anchored to the bottom of the organ chamber, and the other was connected to a strain-gauge for measurement of isometric force (Grass FTO3, Grass Instrument Company, Quincy, MA). The rings were placed at the optimal point of their length-tension relation by progressively stretching them until contraction to potassium ions $(20 \mathrm{mM})$, at each level of distension, was maximal (13). In all experiments, the presence or absence of endothelium was confirmed by determining the response to 1 $\mu \mathrm{M}$ acetylcholine in rings contracted with 20 $\mathrm{mM}$ potassium ions $(9,13)$. After optimal tension was achieved, the arterial segments were allowed to equilibrate for $30-45 \mathrm{~min}$ before administration of drugs.

\section{Drugs}

The following drugs were used: acetylcholine chloride, indomethacin, lipopolysaccharide serotype 10(Habs) from Pseudomonas aeruginosa, prostaglandin $\mathrm{F}_{2 \alpha}$ (Sigma Chemical Co., St. Louis, MO), L-arginine, $\mathrm{D}$-arginine, and $\mathrm{N}^{\mathrm{G}}$-monomethyl-L-arginine 
(Calbiochem, San Diego, CA). All powdered drugs were prepared with distilled water except for indomethacin, which was dissolved in $10 \mu \mathrm{M} \mathrm{Na}{ }_{2} \mathrm{CO}_{3}$. Concentrations are reported as final molar concentration in the organ chambers.

\section{Data analysis}

Results are reported as mean \pm SEM. In all experiments, $\mathrm{N}$ refers to the number of animals from which blood vessels were taken. Responses are reported as percent change from the contracted levels. We considered only the data for each vessel with and without endothelium. Since we did not compare the data for the five different vessels assayed in each experiment, statistical evaluation was performed only by Student $t$-test for either paired or unpaired observations. Values were considered to be statistically significant when $\mathrm{P}$ was less than 0.05 .

\section{Results}

Coronary artery segments with and without endothelium exhibited comparable contraction in response to $2 \mu \mathrm{M}$ prostaglandin $\mathrm{F}_{2 \alpha}(5.43 \pm 0.92 v s 4.02 \pm 0.08 \mathrm{~g}$ for arteries with and without endothelium, $\mathrm{N}=6$ ). After the contraction in response to prostaglandin was stable, administration of increasing concentrations of Pseudomonas LPS (0.05-0.50 $\mathrm{mg} / \mathrm{ml}$ ) caused significant vasodilation in arteries with endothelium, but no significant change in tension in arteries without endothelium (Figures 1 and 2). The endotheliumdependent vasodilator response to LPS was inhibited by incubating the coronary arterial segments with $10 \mu \mathrm{M}$ L-NMMA, a competitive inhibitor of nitric oxide synthesis from $\mathrm{L}$-arginine, at least $10 \mathrm{~min}$ prior to contraction with prostaglandin $\mathrm{F}_{2 \alpha}$ (Figure 2). LNMMA caused no significant consistent change in tension in arterial segments with or without endothelium. Contraction in response to $2 \mu \mathrm{M}$ prostaglandin $\mathrm{F}_{2 \alpha}$ following
L-NMMA treatment was $5.76 \pm 1.02$ for arteries with endothelium $v s 4.95 \pm 0.69 \mathrm{~g}$ for arteries without endothelium $(\mathrm{N}=6)$.

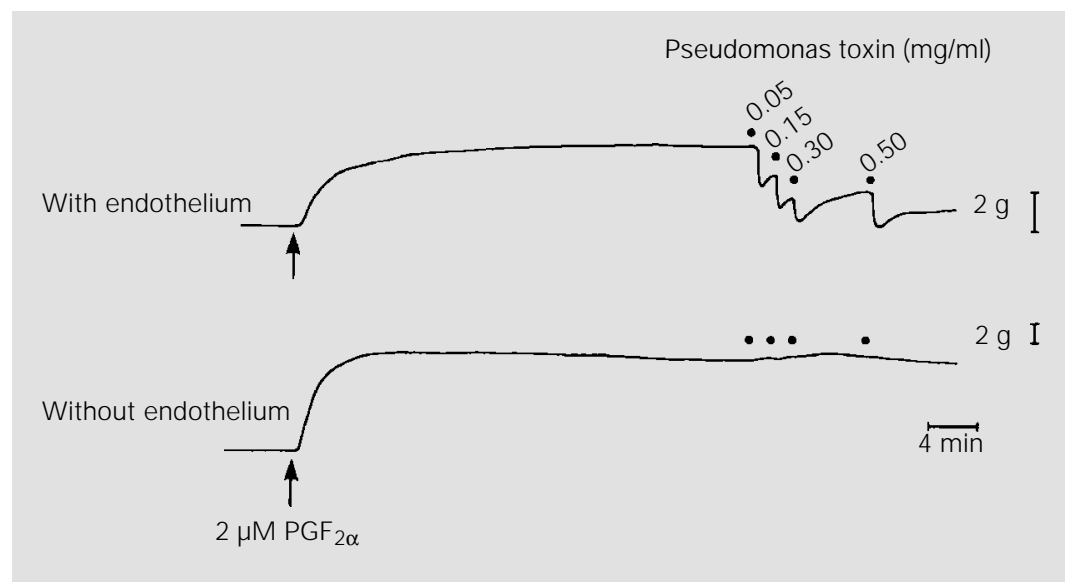

Figure 1 - Isometric tension recording of the effect of Pseudomonas aeruginosa lipopolysaccharide on canine epicardial coronary arteries (original tracing). Segments of left circumflex coronary artery, with and without endothelium, were suspended in organ chambers to measure isometric force. Segments were contracted with $2 \mu \mathrm{M}$ prostaglandin $\mathrm{F}_{2 \alpha}\left(\mathrm{PGF}_{2 \alpha}\right)$. When the contraction in response to prostaglandin was stable, the vessels were exposed to increasing concentrations of endotoxin ( 0.05 to $0.50 \mathrm{mg} / \mathrm{ml})$.

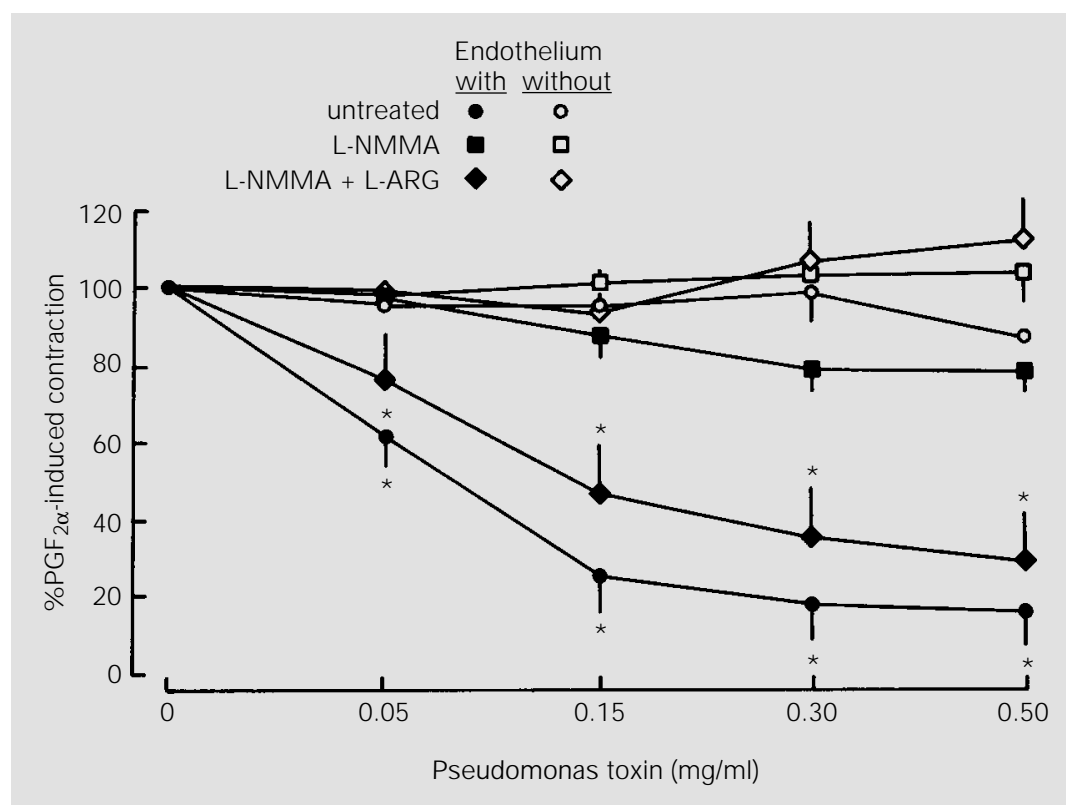

Figure 2 - Concentration-response relationship for Pseudomonas aeruginosa lipopolysaccharide in canine coronary arteries ( $N=6$ per group). Segments were contracted with $2 \mu \mathrm{M}$ prostaglandin $\mathrm{F}_{2 \alpha}\left(\mathrm{PGF}_{2 \alpha}\right)$ (initial tension) and exposed to increasing concentrations of endotoxin $(0.05-0.50 \mathrm{mg} / \mathrm{ml})$. Results are reported as means $\pm \mathrm{SEM}$. L-NMMA denotes the presence of $10 \mu \mathrm{M} \mathrm{NG-monomethyl-L-arginine.} \mathrm{L-NMMA} \mathrm{+} \mathrm{L-ARG} \mathrm{denotes} \mathrm{the} \mathrm{presence} \mathrm{of}$ $10 \mu \mathrm{M} \mathrm{NG}$-monomethyl-L-arginine and $100 \mu \mathrm{M}$ L-arginine. $* P<0.05$ compared to the initial tension of coronary artery segments (Student t-test). 
The inhibition of LPS-mediated vasodilation by L-NMMA could be reversed by the addition of exogenous $100 \mu \mathrm{M}$ L-arginine but not by $100 \mu \mathrm{M}$ D-arginine (Figure 2).

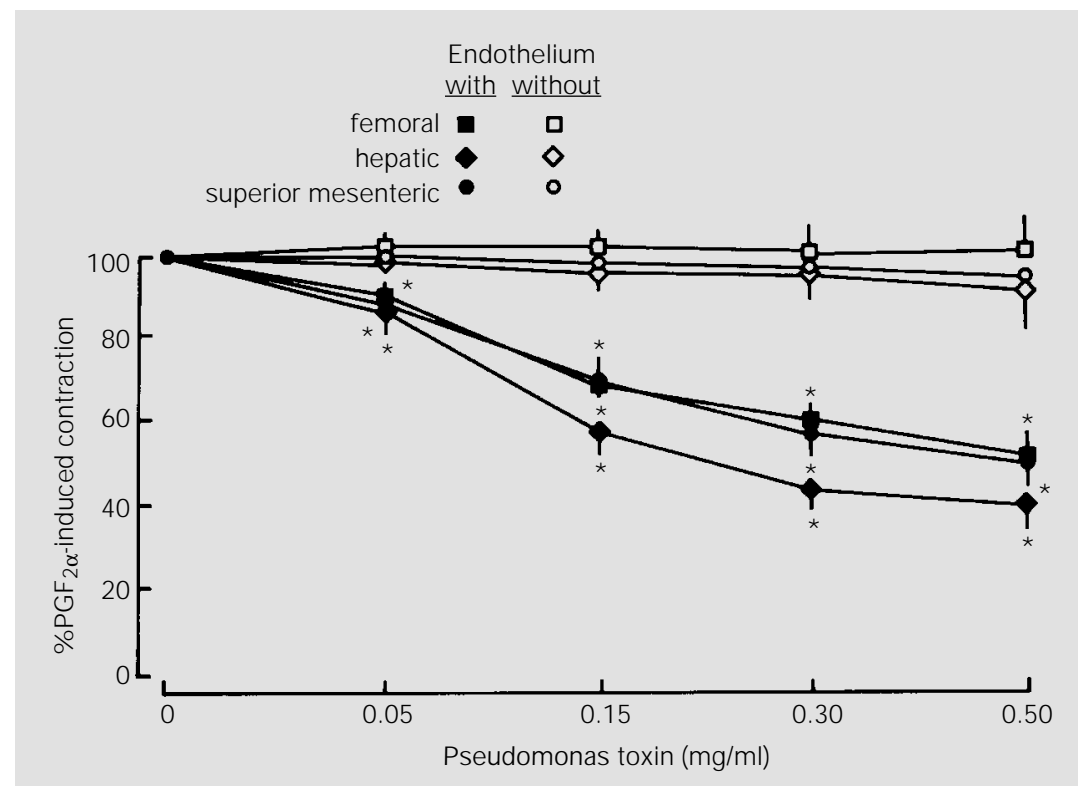

Figure 3 - Concentration-response relationship for Pseudomonas aeruginosa lipopolysaccharide of canine femoral, hepatic, and superior mesenteric arteries ( $\mathrm{N}=6$ per group). Segments were contracted with $2 \mu \mathrm{M}$ prostaglandin $\mathrm{F}_{2 \alpha}\left(\mathrm{PGF}_{2 \alpha}\right)$ (initial tension) and exposed to increasing concentrations of endotoxin $(0.05-0.50 \mathrm{mg} / \mathrm{ml})$. Results are reported as means \pm SEM. $* \mathrm{P}<0.05$ compared to the initial tension (Student $\mathrm{t}$-test).

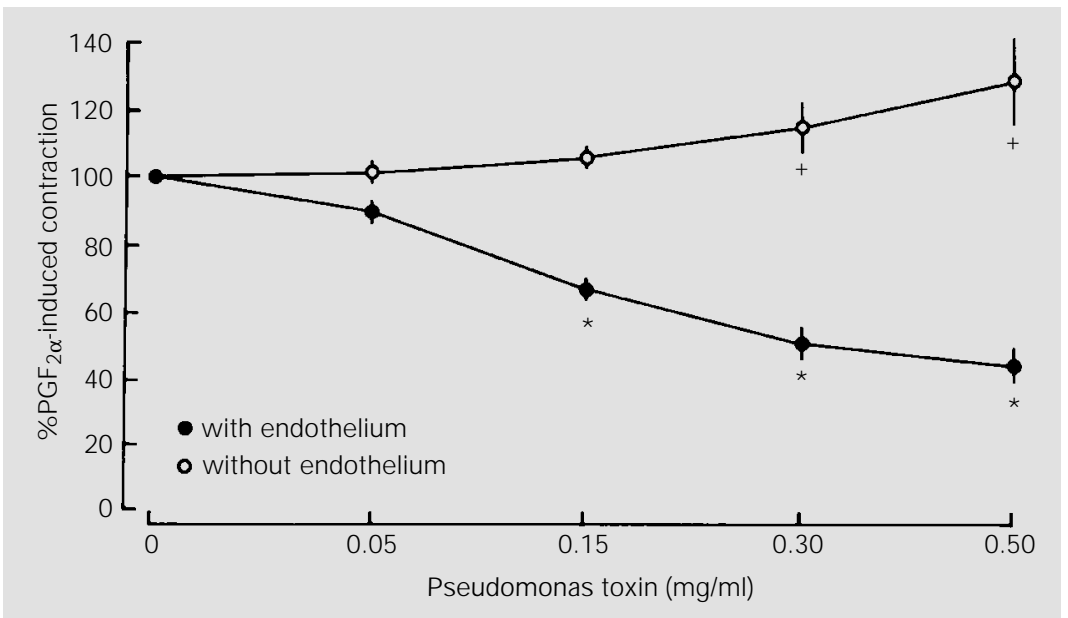

Figure 4 - Concentration-response relationship for Pseudomonas aeruginosa lipopolysaccharide in canine renal arteries $(\mathrm{N}=6)$. Segments were contracted with $2 \mu \mathrm{M}$ prostaglandin $\mathrm{F}_{2 \alpha}\left(\mathrm{PGF}_{2 \alpha}\right)$ (initial tension) and exposed to increasing concentrations of endotoxin (0.05$0.50 \mathrm{mg} / \mathrm{ml})$. Results are reported as means $\pm \mathrm{SEM}$. $* \mathrm{P}<0.05$ compared to the initial tension of arterial segments with endothelium (Student t-test). $+\mathrm{P}<0.05$ compared to initial tension of arterial segments without endothelium (Student t-test).
Canine arteries with and without endothelium exhibited the following contraction in response to $2 \mu \mathrm{M}$ prostaglandin $\mathrm{F}_{2 \alpha}(\mathrm{N}=6$ per group): femoral artery, $3.67 \pm 0.42 v s$ $5.30 \pm 0.70 \mathrm{~g}(\mathrm{P}<0.05)$; hepatic artery, $8.30 \pm$ 1.31 vs $4.67 \pm 0.91 \mathrm{~g}(\mathrm{P}<0.05)$; superior mesenteric artery, $9.03 \pm 1.12$ vs $14.42 \pm$ $1.18 \mathrm{~g}(\mathrm{P}<0.05)$, and renal artery, $8.37 \pm 1.46$ vs $10.38 \pm 1.74 \mathrm{~g}$, respectively. In contracted canine renal, femoral, hepatic, and superior mesenteric arteries, Pseudomonas LPS (0.05$0.50 \mathrm{mg} / \mathrm{ml}$ ) induced concentration-dependent decreases in tension $(\mathrm{P}<0.05$, all groups $)$. In contracted femoral, hepatic, and superior mesenteric arteries without endothelium, Pseudomonas LPS $(0.05-0.50 \mathrm{mg} / \mathrm{ml})$ caused no significant change in tension (Figure 3 ). However, in the renal artery without endothelium, LPS induced a significant increase in tension (to $129 \pm 13.5 \%$ of the initial contraction in response to prostaglandin $\mathrm{F}_{2 \alpha}$ at the highest concentration tested $(\mathrm{N}=6$, $\mathrm{P}<0.05)$ ) (Figure 4).

\section{Discussion}

In the present experiment, Pseudomonas LPS induced endothelium-dependent relaxation of the canine femoral, renal, superior mesenteric, hepatic, and epicardial coronary arteries. The LPS concentrations $(0.05$ to $0.50 \mathrm{mg} / \mathrm{ml}$ ) were estimated in previous experiments with progressive dilutions until an isometric tension recording without complete relaxation was obtained in response to a single concentration. Vasorelaxation was prevented by removing the intima of the blood vessel, and cannot be attributed to a prostanoid, since all experiments were performed in the presence of the cyclooxygenase inhibitor indomethacin. To further identify the mechanism of lipopolysaccharide-mediated endothelium-dependent vasodilation, we treated segments of epicardial coronary artery with L-NMMA, an inhibitor of nitric oxide synthesis from L-arginine (14), which blocked endothelium-depend- 
ent relaxation to the toxin. The specificity of the blocker for the L-arginine pathway was further substantiated by the finding that the inhibition of vasodilatation by L-NMMA could be reversed by exogenous L-arginine (15).

A MEDLINE search about nitric oxide and sepsis, since EDRF was identified as nitric oxide, showed about 350 published papers. Most of the studies were done using cell cultures. In vitro studies using "organ chambers" were a minority, reflecting, for sure, limitations of this methodology. In fact, we tried to study another bacterial lipopolysaccharide without obtaining a uniform vascular reactivity response. A survey of this bibliography did not show any study using Pseudomonas LPS as a pharmacological tool to study endothelium function in "organ chambers". Still concerning the methodology, it is important to emphasize that injection of bacterial endotoxins administered to animals at a low dose $(30-40 \mu \mathrm{g} / \mathrm{kg})$ can cause hypotension. In vivo, bacterial toxins act to trigger systemic inflammatory reactions through cytokines and, perhaps, this should explain the higher doses used in the present in vitro study.

Three isozymes of nitric oxide synthase (NOS) have been identified and the cDNAs for these enzymes have been isolated. In humans, isozymes I (in neuronal and epithelial cells), II (in cytokine-induced cells), and III (in endothelial cells) are encoded by three different genes located on chromosomes 12, 17, and 7, respectively. Expression of isoform II of NOS can be induced with lipopolysaccharide and cytokines in many different cells. NOS II is not regulated by $\mathrm{Ca}^{2+}$; it produces large amounts of NO that has cytostatic effects on parasitic target cells by inhibiting iron-containing enzymes and causing DNA fragmentation. Induced NOS II (NOSi) is involved in the pathophysiology of autoimmune diseases and septic shock (16). Investigations by Knowles et al. (17) and others $(18,19)$ have demonstrated that exposure to endotoxin stimulates the expression of an inducible form of the nitric oxide synthase enzyme (NOSi) within smooth muscle cells of the peripheral vasculature. The resulting increase in nitric oxide formation is so great that the vasodilation produced cannot be overcome by administration of direct vasoconstrictors. Interestingly, glucocorticoids, which inhibit the expression of the inducible form of NOS (20), prevent the progressive late fall in vascular tone following exposure to endotoxin in vitro (14). These experiments established that activation of NOSi in vascular smooth muscle is the cause of hypotension late in sepsis, but the data did not explain the early systemic arterial hypotension that is a common clinical feature of sepsis. In our experiments we used only LNMMA as a blocker of nitric oxide synthesis, which acts by inhibiting both synthases (constitutive NOS (NOSc) and NOSi). We did not use specific NOSi blockers such as glucocorticoids (14) and more recent agents such as aminoguanidine (21), L-canavanine (22), N6-(1-iminoethyl) lysine (L-NIL), and 2,4-diamino6-hydroxy-pyrimidine (23), but the results of all studies using this approach are consistent with the current concept of a pivotal role of NOSi in late sepsis. Emergent new concepts have established that NOSi should act early because protein synthesis should occur within a very short time, but in vivo experiments, and even molecular biology experiments, show the importance of NOSi late in sepsis (24).

On the basis of our experimental data and of the studies cited previously, we postulate the following mechanism for the development of hypotension in Pseudomonas septicemia. Initially, Pseudomonas LPS acts on the peripheral vasculature to stimulate endothelial cell synthesis of nitric oxide from Larginine via activation of NOSc. As our experiments indicate, this vasodilator effect of Pseudomonas LPS on the endothelium can be inhibited by L-NMMA. In this early phase of sepsis, the vascular smooth muscle does 
not contribute to NO synthesis and may respond to intravenous vasoconstrictors. However, in late sepsis, hypotension may progress to an irreversible stage (septic shock) because endotoxin stimulates synthesis of the NOSi in the vascular smooth muscle. Peripheral vascular smooth muscle would then produce nitric oxide, which, by inducing tonic vasodilation of the blood vessels via a cyclic GMP-dependent mechanism, would make the vascular smooth muscle unresponsive to vasoconstrictor agents. Therapies directed toward the nitric oxide pathway might be effective in counteracting the early and late phases of hypotension associated with Pseudomonas endotoxemia.

\section{References}

1. Dudley MN (1990). Overview of gram negative sepsis. American J oumal of Hospital Pharmacy, 47 (Suppl 3): S3-S6.

2. Fairman RP \& Glauser FL (1980). Pathophysiologic alterations in endotoxemia. Similarities to an animal model. Archives of Internal Medicine, 140: 788-790.

3. Lechi $A$, Arosio $E$, Pancera $P$, Anesi $P$, Zannini G, Todeschini G \& Cetto G (1984). Pseudomonas septicemia. A review of 60 cases observed in a university hospital. J ournal of Hospital Infection, 5: 29-37.

4. Miller PJ \& Wenzel RP (1987). Etiologic organisms as independent predictors of death and morbidity associated with bloodstream infections. J ournal of Infectious Diseases, 156: 471-477.

5. Parratt J R (1989). Alterations in vascular reactivity in sepsis and endotoxemia. In: Vincent J L (Editor), Update in Intensive Care. Vol X. Springer-Verlag, Berlin, 299308.

6. Nathanson C, Eichenholz PW, Danner RL, Eichacker PQ, Hoffman WD, Kuo GC, Banks SM, MacVittie TJ \& Parrillo JE (1989). Endotoxin and tumor necrosis factor challenges in dogs simulate the cardiovascular profile in human septic shock. J ournal of Experimental Medicine, 169: 823-832.

7. Kopolovic R, Thrailkill KM, Martin DT, Carey LC \& Cloutier CT (1986). A critical comparison of the hematologic, cardiovascular, and pulmonary response to steroids and non-steroidal anti-inflammatory drugs in a model of sepsis and adult respiratory distress syndrome. Surgery, 100: 679-690.

8. Atik M, Liu PV, Hanson BA, Amini $S \&$ Rosenberg CF (1968). Pseudomonas endotoxin shock. A preliminary report of studies in the dog. J ournal of the American Medical Association, 205: 134-140.

9. Furchgott RF \& Zawadzki J V (1980). The obligatory role of endothelial cells in the relaxation of arterial smooth muscle by acetylcholine. Nature, 288: 373-376.
10. Ignarro LJ , Buga GM, Wood K, Byrns RE \& Chaudhuri G (1987). Endothelium-derived relaxing factor produced and released from artery and vein is nitric oxide. Proceedings of the National Academy of Sciences, USA, 84: 9265-9269.

11. Palmer RMJ, Ferrige AG \& Moncada $S$ (1987). Nitric oxide accounts for the biological activity of endothelium-derived relaxing factor. Nature, 327: 524-526.

12. Ignarro LJ, Lippton $\mathrm{H}$, Edwards J C, Baricos WH, Hyman AL, Kadowitz PJ \& Gruetter CA (1981). Mechanism of vascular smooth muscle relaxation by organic nitrates, nitrites, nitroprusside, and nitric oxide: Evidence for involvement of S-nitrosothiols as active intermediates. J ournal of Pharmacology and Experimental Therapeutics, 218: 739-749.

13. Pearson PJ, Schaff HV \& Vanhoutte PM (1990). Acute impairment of endotheliumdependent relaxations to aggregating platelets following reperfusion injury in canine coronary arteries. Circulation Research, 67: 385-393.

14. Rees DD, Palmer RMJ, Hodson HF \& Moncada S (1989). A specific inhibitor of nitric oxide formation from L-arginine attenuates endothelium-dependent relaxation. British J ournal of Pharmacology, 96: 418-424.

15. Palmer RMJ , Ashton DS \& Moncada S (1988). Vascular endothelial cells synthesize nitric oxide from L-arginine. Nature, 333: 664-666.

16. Förstermann U, Closs El, Pollock JS, Nakane M, Schwarz P, Gath I \& Kleinert H (1994). Nitric oxide synthase isozymes. Characterization, purification, molecular cloning, and functions. Hypertension, 23 (Part 2): 1121-1131.

17. Knowles RG, Salter M, Brooks SL \& Moncada S (1990). Anti-inflammatory glucocorticoids inhibit the induction by endotoxin of nitric oxide synthesis in lung, liver, and aorta of the rat. Biochemical and Biophysical Research Communications, 172:
1042-1048.

18. Fleming I, J uluo-Schaeffer G, Gray GA Parrat J R \& Stoclet J E (1991). Evidence that an L-arginine/nitric oxide-dependent elevation of tissue cyclic GMP content is involved in depression of vascular reactivity by endotoxin. British J ournal of Pharmacology, 103: 1047-1052.

19. Fleming I, Gray GA, Schott $C \&$ Stoclet J (1991). Inducible but not constitutive production of nitric oxide by vascular smooth muscle cells. European J ournal of Pharmacology, 200: 375-376.

20. Radomski MW, Palmer RMJ \& Moncada S (1990). Glucocorticoids inhibit the expression of an inducible, but not constitutive, nitric oxide synthase in vascular endothelial cells. Proceedings of the $\mathrm{Na}$ tional Academy of Sciences, USA, 87: 10043-10047.

21. Scott J Á, Machoun M \& McCormack DG (1996). Inducible nitric oxide synthase and vascular reactivity in rat thoracic aorta: effect of aminoguanidine. J ournal of Applied Physiology, 80: 271-277.

22. Liaudet L, Feihl F, Rosselet A, Markert M, Hurni J M \& Perret C (1996). Beneficial effects of L-canavanine, a selective inhibitor of inducible nitric oxide synthase, during rodent endotoxaemia. Clinical Science, 90: 369-377.

23. Schwartz D, Mendonca M, Schwartz I, Xia $Y$, Satriano J, Wilson CB \& Blantz RC (1997). Inhibition of constitutive nitric oxide synthase (NOS) by nitric oxide generated by inducible NOS after lipopolysaccharide administration provokes renal dysfunction in rats. J ournal of Clinical Investigation, 100: 439-448.

24. Liu SF, Barnes PJ \& Evans TW (1997) Time course and cellular localization of lipopolysaccharide-induced inducible nitric oxide synthase messenger RNA expression in the rat in vivo. Critical Care Medicine, 25: 512-518. 